\title{
SALA DE AULA: ESPAÇO PEDAGÓGICO PARA VIVER E APRENDER ARTE
}

Classroom, Space for Living and Learning Art Reading and Re-Reading of Art Work

Alexandre Silva dos Santos Filho ${ }^{13}$

\begin{abstract}
RESUMO
A importância do professor saber ler uma imagem visual é imprescindível para que também possa possibilitar a seus alunos a experiência de entrar em contato com o conteúdo objetivo e subjetivo das obras artísticas. Otto Dix e Lassar Segal trabalharam a temática guerra, muito oportuna para ser discutida como tema da arte e vivência atual sobre as guerras e o terrorismo no mundo. $O$ objetivo principal dessa experiência por meio da leitura e releitura de obras de arte foi promover um encontro com professores leigos em arte que, ao mesmo tempo, estavam trabalhando a disciplina em sala de aula, mas que não tinham nenhuma experiência com a arte e a sua história. Dessa forma, tornou-se oportuno realizar a alfabetização estético-visual e o conhecimento da gramática visual numa oficina promovida pela Universidade Federal do Pará - Campus de Marabá pelo Núcleo de Arte Educação Sul e Sudeste do Pará e projeto Arte na Escola.
\end{abstract}

Palavras-chave: Leitura de imagem; alfabetização estético-visual; arte; professor.

\begin{abstract}
The importance of the professor knowing how to read visual image is essential to that students be able to be in touch with the objective and subjective contents of the artistic works. Otto Dix and Lassar Segal work the theme "war", very timely to be discussed as an art theme and actual experiences about the wars and terrorism in the world. The main objective of this experience through reading and re-reading of the art work was to promote a meeting with professor lay in art that, at the same time, were working the discipline in the classroom, but did not have any experience with art and its history. In this way, it has became timely to achieve the aesthetic-visual literacy and the knowing of the visual grammar in a workshop promoted by Universidade Federal do Pará - Campus de Marabá (Federal University of Pará Campus of Marabá) through the Núcleo de Arte-Educação do Sul (Core of artEducation South) and Sudeste $d$ Pará (Southeast of Pará) and projet Art at School.
\end{abstract}

Keywords: Reading of image; aesthetic-visual literacy; art; professor.

\footnotetext{
${ }^{13}$ Professor na Universidade Federal do Pará, Coordenador do Arte na Escola UFPA - Campus de Marabá, Mestre em Comunicação e Cultura Contemporânea e doutorando em educação na UFG. Rua 226, Qd.67C, Lt.10, №894, apto. 102, Ed. Milão, CEP 74610-130, Goiânia-Go. Fone (62) 32616601/81697139. E-mail: alixandresantos@gmail.com
} 


\section{RESUMEN}

La importancia de que el profesor sepa leer imagenes visuales es esencial para possibilitar a sus alumnos la experiencia de tener contacto con el contenido objetivo y subjetivo de las obras esteticas. Otto Dix y Lassar Segall se preocuparon con la tematica guerra, muy oportuna para ser discutida como tema de la arte y vivencia actual sobre las guerras y el terrorismo en el mundo. El objetivo principal de nuestas acciones para la lectura y (re)lectura de obras de arte y historia del arte fue permitir que profesores no formados en arte, pero que esenavan este contenido, tubieran esta experiencia. Desta forma, fue oportuno realizar la alfabetizacion estetico visual y apresentar lo que es gramatica visual en la Universidade Federal del Para Campus de Maraba, por el nucleo de Arte Educacion Sur y Sudeste del Para y el Projecto Arte na Escola.

Palabras-clave: lectura de imagenes visuales; alfabetizacion estetico-visual; Arte; profesor.

"Gostar de Aprender Arte" foi o tema escolhido para a realização do Seminário de Educação Continuada, promovido pelo Projeto Arte na Escola e Núcleo de Arte-Educação do Sul e Sudeste do Pará, inspirado no livro da professora Rosa lavelberg (2003). O evento atendeu cerca de cem (100) participantes - do ensino fundamental e médio - ligados à rede de ensino público nas regiões do sul e sudeste do Pará. Este tipo de atividade (voltada exclusivamente ao ensino da arte) é realização inédita da UFPA - Campus de Marabá. O evento focalizou exclusivamente o professor que atua na sala de aula com a seguinte particularidade: nenhum professor (participante) tem formação específica em arte, daí a grande dificuldade do ensino na região.

É importante ressaltar que a arte sempre esteve desvinculada do ensino na instituição escolar e que somente a partir da LDB, Lei $n^{\circ} 9394 / 96$, $\S 2^{\circ}$, é que foi criada a obrigatoriedade do ensino de arte no Brasil. A partir daí, a arte foi introduzida na Educação Infantil, no Ensino Fundamental do $1^{\circ}$ ao $5^{\circ}$ ano, mantendo-a nos $6^{\circ}$ ao $9^{\circ}$ anos $^{14}$ e no Ensino Médio, extinguindo assim a antiga Educação Artística.

Entretanto, isso motivou o aparecimento de alguns problemas relacionados, principalmente, com a regência da disciplina. No caso específico do $6^{\circ}$ ao $9^{\circ}$ ano do Ensino Fundamental, as instituições de ensino superiores mantêm curso de licenciatura em artes somente na capital. No sul e sudeste do Pará, a situação é

\footnotetext{
${ }^{14}$ Antigas $5^{\text {as }}$ a $8^{\text {as }}$ séries do Ensino Fundamental.
} 
constrangedora porque não existe curso de formação em arte, resultando em uma dificuldade para a área. Do mesmo modo, na esfera da Educação Infantil e séries iniciais do Ensino Fundamental, tornou-se eminentemente difícil dizer, na prática, quem seria o ministrante dessa disciplina na escola, apesar de as Secretarias de Educação dos Municípios (do sul e sudeste do Pará) insistirem em conceder esta tarefa ao professor unidocente com formação múltipla.

Desse modo, perseveram as questões: se o professor unidocente não tem formação específica em arte, o que ele ensina na escola? Por que ele tem que dar conta do ensino da arte na escola, já que para ensinar arte é indispensável que o docente tenha vivência com a linguagem artística, conhecimentos teóricos e práticos de arte, bem como saber promover a experiência estética? Em geral, é evidente que o professor, tanto da capital como do interior do Estado do Pará, sinta grandes dificuldades para trabalhar a arte na escola. Existem certas restrições ao professor, tal como o acesso às produções artísticas nos diversos âmbitos da arte regional, nacional e internacional. Este distanciamento dos produtores culturais acaba gerando uma deficiência na vivência do próprio professor e reflete sensivelmente em seus alunos uma exclusão ao patrimônio de bens culturais e ao uso de uma metodologia de ensino adequada.

A dificuldade torna-se amplamente perversa quando estamos diante do fato de que existem professores leigos de arte, os quais se aventuram a ensinar o que não sabem. É escandalosa essa desventura. E poder-se-ia alcunhá-los de "aventureiros do tempo vazio", porque nada ensinam, já que não o podem fazer sem que se tenham aprendido primeiramente. Estes professores confundem obra de arte com artesanato e - tamanha é a insensatez dos regrados senhores que dispõem de poderes para atribuir desígnios no ato da lotação a docentes - nem ao menos foram alfabetizados em arte e acabam tornando-se alfabetizadores dela na escola (esse é o caso específico dos professores do $6^{\circ}$ ao $9^{\circ}$ ano do Ensino Fundamental do sul e sudeste do Pará).

Do mesmo modo, percebe-se que a "insensatez apraz a morbidez". Os lotados para o ensino artístico, apesar do esforço, muitos são incapazes de reconhecer a importância da arte-educação na escola. Contudo, por uma razão que não é a dificuldade somente, eles assumem a disciplina por causa da sua carga horária a ser completada. Essa condição contingente acaba se revelando como esdrúxula, já que saber arte não é o objetivo principal para se construir o ensino 
artístico na escola. Desse modo, a escola é invadida por professores que se arriscam a ensinar arte sem ao menos, conhecer a história da arte como ponto de partida para a ampliação do conhecimento das crianças, além de contribuir para a alfabetização verbal e não-verbal. Na verdade, estamos diante de um grande paradoxo educacional artístico: professores que assumem o ensino de arte e que não sabem como lidar com ela. Dessa forma, que importância tem a alfabetização visual ou estética na escola se o professor não responde à linguagem da arte?

Devido à preocupação com esse contexto discrepante, criou-se o Núcleo de Arte-Educação do Sul e Sudeste do Pará, apoiado pelo Projeto Arte na Escola, com o propósito de atender a formação de professores leigos em Arte e que muito necessitam de apoio para o desenvolvimento de seus projetos na escola. Isso é de interesse público, já que a educação desses deverá refletir a possibilidade de continuação do trabalho que se insere neste âmbito, ou seja, o propósito fundamental é possibilitar o uso da linguagem artística por meio da alfabetização para e com a imagem da arte e, oferecer a esses professores a oportunidade de se tornarem alfabetizadores estético-visuais.

\begin{abstract}
É necessário que o professor seja um estudante fascinado por arte, pois só assim terá que ensinar e transmitir a seus alunos a vontade de aprender. Nesse sentido, um professor mobilizado para a aprendizagem contínua, em sua vida pessoal e profissional, saberá ensinar essa postura a seus estudantes. (IAVELBERG, 2003, p. 12)
\end{abstract}

De acordo com lavelberg, sem fascinação pela arte é difícil empreendermos uma educação continuada. É primordial que o professor esteja estimulado para envolver-se com o estudo e a reflexão da arte na escola e que amplie o pensar crítico, valorizando as atividades em sala de aula como forma de impulsionar uma revolução estética capaz de influir na qualidade de vida das crianças com as quais trabalha na escola. Enfim, desejamos que os professores da região sul e sudeste do Pará se disponibilizem em participar de grupos de estudos, desenvolvam práticas de ver e conhecer a arte e que possam realizar projetos de ocupação dos espaços culturais da escola e da cidade onde moram. Desse modo, demonstrarão interesse pela arte e cultura da região em conexão com o mundo da grande arte e compreenderão que a arte faz parte da vida de todos. 
A guerra como tema e a linha como gramática visual

Com o desenrolar dos acontecimentos, tornou-se necessário seguir etapas a fim de envolver o "professor leigo" em arte. Propôs-se iniciar a oficina de alfabetização visual com o significado da sintaxe da linha como semântica que se mostra através da forma, dada visualmente pelas obras de Otto Dix (1891-1969) e Lasar Segall (1891-1957). Diante do preposto e da qualidade artística selecionada (as imagens reproduzidas das obras dos artistas), ofereceu-se a oportunidade aos professores de poder dialogar entre si - um momento de contemplação e troca de idéias - a fim de que pudessem abrir espaço para a apreensão dos significados e decodificação da mensagem posta nas imagens artísticas das obras de arte.

Dix e Segall ${ }^{15}$, ambos de origem estrangeira, serviram para impulsionar o olhar dos professores contempladores com suas gravuras, num jogo entre a sensibilidade e o entendimento da poética dos artistas de grandes possibilidades sensoriais e visuais. Assim, construiu um percurso por meio de um diálogo estabelecido entre a obra do artista e o olhar do expectador.

Poder-se-ia indagar sobre o porquê desses dois artistas. A justificativa seria pelo fato de que tanto Dix quanto Segall são artistas contemporâneos que interpretaram a realidade sobre a segunda guerra mundial se valendo de técnicas da gravura em metal, demonstrando aos nossos olhares o contexto das atrocidades. Isso traz uma conotação à realidade emergente em que vivemos na atualidade quando em torno de nossas vidas acabamos envolvidos com os mesmos sentimentos de mortes, perdas, violências, traumas etc. Segall diz que "... real e imaginário são ingredientes que se enfrentam, com plena consciência, na razão histórica do presente, apoiados sempre no sentido místico" (SEGAL apud RIBEIRO, 2002). Percebe-se a visão de um homem atormentado pela presença do terror diante da morte dos seus conterrâneos, o pavor, a fome e a miséria.

Dix, abalado pela pressão das recordações da guerra, "[...] retrata as crueldades vistas nos campos de batalha em gravuras carregadas de profunda pressão emocional e tensão visual" (Ibidem). Ele expressa a visão da guerra nas

${ }^{15}$ Os dois artistas se conheceram na cidade alemã de Dresden ao término da Primeira Grande Guerra. Compartilhando os ideais do Expressionismo alemão - que os levou, com outros artistas, à criação da Secessão de Dresden, Grupo 1919 -, Otto Dix e Lasar Segall produziram obras de distintas poéticas pessoais, mas que possibilitaram estimulantes comparações (RIBEIRO, 2002, p.05). 
trincheiras, mostrando seus companheiros mortos e em decomposição na lama do campo de batalha. Dessa forma, a visão desses artistas perpassa o tempo, e o professor participante do seminário "Gostar de Aprender Arte" testemunha um tempo vivido, sendo ele a terceira visão da guerra, sem estar nos escombros ou nas trincheiras, mas consciente dela, da sua existência, presenciado por uma mídia escrita e televisual em seus lares.

Ao considerarmos a guerra um fato contemporâneo presente em nossas vidas, estamos evidenciando-a, principalmente, pela existência do terrorismo e da violência crescentes em nossas cidades. O combate destes é visível em toda a parte do globo. O professor é testemunha de uma guerra existente no mundo, que não se vê, porém a reconhece muito bem porque está em contato diariamente com as notícias narradas nos documentários e noticiários da televisão, pelas imagens bem elaboradas de filmes com esse tema, além das fotografias em revistas. A guerra é algo que não se pode deixar de lado sem percebê-la. Ela é marcante em nossas vidas, contudo, no nosso caso, de cidadão brasileiro, pouco se sabe, realmente, sobre o seu efeito na sociedade. Por isso é que não podemos evitar este tema e virar o rosto sem nos importar.

Um outro aspecto desta justificativa é o fator artístico, a gramática visual, o elemento sintático que une os dois artistas: a linha. A linha é o elemento da semântica visual que tratamos como uma unidade de informação sensorial, gerando significantes e significados nas obras desses dois talentos.

Assim, a linha ao se tornar o elemento sintático revelador da expressão artística de Dix e Segall, revela também a personalidade de cada um e é percebida pelos contempladores/professores a partir da leitura que se estrutura na forma de imagem visual. A leitura da imagem é outro passo que foi trabalhado usando as obras desses artistas. Tal proposição requisita que o aprendente se torne um inquisidor das mensagens através dos elementos visuais, por isso detivemo-nos em pensar a linha sob seu aspecto sintático.

Recorremos ao conceito de leitura de imagem proposto por Pillar (1003, p.77), que bem o define: "Ler uma imagem é compreendê-la, interpretá-la, descrevê-la, decompô-la e recompô-la para apreendê-la como objeto a conhecer". Dessa forma, também propusemos usar o roteiro baseado em etapas, tais como: descrição, 
análise, interpretação, fundamentação e releitura, explicitadas desse modo, com base em Pillar (1992, p. 79-82):

A descrição diz respeito à identificação do titulo do trabalho do artista que o fez, do lugar e da época em que a imagem foi criada, da linguagem plástica empregada, do material utilizado, do tipo de representação, se figurativa ou abstrata, entre outros. A técnica usada no trabalho é essencial para identificar o modo como a imagem parece ter sido elaborada, ou seja, como aparentemente o pintor usou o pincel, que tipo de instrumento e que método artístico ele teria empregado.

A análise procura discriminar as relações entre os elementos formais da imagem: o que as formas criam entre si, como elas se influenciam e se relacionam. Examinam-se relações de tamanho, relação entre as formas, relações de cor e de textura, de superfícies texturizadas e lisas, de espaço e de volume. É muito importante também o modo como as formas estão dispostas, pois dependendo da disposição horizontal, vertical ou diagonal, mudam-se as relações entre elas.

Interpretar é organizar as observações de modo significativo, ou seja, é conectar idéias que explicam sensações e sentimentos experimentados frente a uma imagem. Pode-se expor "um problema que o trabalho parece ter tentado resolver." (FELDMAN, 1970, p.362 apud PILLAR) Segundo o ponto de vista de quem está interpretando.

Fundamentação é conhecer o artista e sua obra, falar do envolvimento dele com o meio em que viveu e relacionar a sua vida artística com o contexto histórico e social da sua época.

Releitura é reinterpretar a obra do artista sob diferentes aspectos e linguagens. Pode ser por meio da poesia, do teatro, da dança, do desenho, da escultura, da pintura etc. Isso demonstra que o observador também participa da construção da idéia da obra juntamente com o artista.

Para que o professor tivesse contato com os aspectos conceituais que envolvem a linha, optamos por fazer uma revisão dos aspectos da unidimensionalidade, da classificação, das sensações transmitidas e da expressividade que se materializam nesses conceitos. Desse modo, nos colocamos em frente dos elementos visuais dos conteúdos que elaboram a forma visual e daqueles que interferem na leitura do apreciador de imagens (o observador). Mesmo que alguém se coloque diante das imagens fixas (obras de arte) - nesse caso as 
gravuras de Dix e Segall - de maneira parcial, há ainda a possibilidade de apreciação artística da obra, posto que se envolvem com uma gama de sensações e interpretações, movimentando seus sentidos e exigindo a participação de sua percepção num jogo entre o entendimento e a imaginação, interagindo esteticamente e mobilizando, além da sensorialidade, a emoção.

\section{Resultado Performático}

A última etapa deste processo culminou em uma releitura das obras dos artistas, já que se considera este momento como a reinterpretação da obra sob diferentes aspectos e linguagens. Assim, a proposta de releitura foi construir três imagens a partir de uma obra de Segall ou Dix, as quais seriam interpretadas no espaço tridimensional. Cada cena organizada em 3D teria dez segundos de "apresentação", já que estas não seriam representadas, e sim apresentadas como criação chamada de "imagem congelada", sem o uso da fala, do som e do movimento. Seria como um quadro que tomou conta do espaço para viver as personagens do mundo real, porém naquele momento imóvel, mas comunicando sensações e pulsando nos corações a beleza da imagem que agora estava viva diante dos olhares de todos e viva nos observadores da imagem.

A seqüência de apresentação das imagens congeladas seguiu um roteiro: primeiramente, o grupo de professores que realizou a releitura deveria responder "o que aconteceu antes?". Em resposta, o grupo apresentou uma cena relacionada à imagem principal, escolhida dentre as obras de Dix ou Segall, e depois criou o que denominamos de ação pictórica no espaço tridimensional, apresentada imóvel, usando as possibilidades dos corpos dos participantes que se transformaram em personagens construídos para compor a cena. A segunda cena tinha como proposta a reprodução da imagem da obra do artista. O desafio enveredou pelo modo de fazer pesquisa visual, abrindo a observação para os detalhes dos elementos que compunham a imagem. Dessa forma, usariam elementos reais para refazer a cena, reformulariam o espaço, recriando cenários e outros elementos pictóricos necessários para se aproximar da imagem escolhida, para ser apresentada no espaço tridimensional e, por fim, a cena responderia: "o que aconteceu depois?" Esta resposta deveria conter uma conclusão a partir da mensagem - tirada da 
gravura central - usando para isso os corpos como elementos pictóricos e plásticovisuais, de forma a fornecer imaginação aos apreciadores ali dispostos.

O resultado é performático. A sensação das imagens é uma volta ao passado. Aparentemente a turma entrou em sintonia com a imagem, confundindo-se com a obra. O ganho disso foi surpreendente, pois a leitura é estabelecida pelo toque, cheiro, sabor, cor, beleza e muito mais. É o verbal que se traduz em não-verbal, ou o não-verbal que se cristaliza em imagens emocionantes.

O professor vivencia a gramática visual e se envolve na pesquisa plástica. A sala de aula virou um laboratório de experimentação estético-artística e sensóriovisual, um ateliê do não-verbal. Por fim, as experiências tornam-se significativas porque houve descobertas dos sentidos das ações. Assim, as obras de Dix e Segall, que pareciam distante do contexto do professor, num primeiro momento, passam a fazer parte de sua vida, pois a vida é arte e entre elas há certa combinação.

Refletindo sobre...

A partir dos dois artistas, Otto Dix e Lasar Segall, o olhar do apreciador neste caso do professor - se transformou em puro exercício de vida e arte. Houve diálogo visual entre as construções sensoriais no espaço tridimensional e as formas gráficas das pranchas das gravuras que foram lidas pelos participantes. Nessa busca, a imagem da guerra foi transformada em uma forma de dizer algo ao espectador por meio da linguagem do expressionismo. Assim, a cristalização da imaginação e a mensagem dos artistas foram reinterpretadas pelos professores por seus próprios corpos, ou seja, viveram a arte.

Os objetivos foram alcançados e reconheceu-se a importância de se experimentar a arte de forma mais integradora e estimulante, capaz de restabelecer proximidades com os elementos táteis-visuais da obra dos artistas expressionistas (Dix e Segall), consolidando-se a alfabetização estético-visual a qual nos propusemos realizar.

Assim, ao compor e decompor a imagem da obra de arte por meio de um processo de leitura e releitura, os professores foram capazes de demonstrar habilidades de fazer, ler e contextualizar a obra no tempo e espaço. Portanto, ao compreenderem os aspectos subjetivos e objetivos existentes na obra de arte, 
entenderam que as possibilidades do uso da imagem, na educação das crianças e jovens, são de importância fundamental, pois é por esse processo que se inicia a crítica à imagem.

\section{REFERÊNCIAS}

IAVELBERG, Rosa. Para gostar de aprender arte: sala de aula e formação de professores. Porto Alegre:Artmed, 2003.

PILLAR, Analice Dutra. A leitura de imagem. In: Pesquisa em artes plásticas. Porto Alegre: Ed. Universidade/ UFRGS/ Associação Nacional dos pesquisadores em Artes Plásticas (ANPAP), 1993.

RIBEIRO, Noêmia. Lasar Segall e Otto Dix: o expressionismo alemão em museus paulistano. In: LASAR SEGAL \& OTTO DIX. Diálogos gráficos. Museu Lasar Segall/ MASP/ IPHAN: São Paulo, 2002.

Texto recebido em 30 jun. 2008.

Texto aprovado em 10 set. 2008. 